\title{
Osteotomi sonrası rehabilitasyon ve spora yeniden dönme
}

\author{
Rehabilitation and return to sports after osteotomy
}

\author{
Tahsin Beyzadeoğlu ${ }^{1,2}$, Koray Başdelioğlu², Kerem Yıldırım,3, Nejla Karaca ${ }^{1}$ \\ ${ }^{1}$ Beyzadeoğlu Klinik, Ortopedi ve Travmatoloji, İstanbul \\ ${ }^{2}$ Haliç Üniversitesi, Sağlık Bilimleri Yüksekokulu, İstanbul \\ ${ }^{3}$ Istanbul Gelişim Üniversitesi, Sağlık Bilimleri Yüksekokulu, İstanbul
}

\begin{abstract}
Diz çevresi osteotomileri sonrası rehabilitasyonun amacı; osteotomi hattı ve fiksasyonuna zarar vermeden, en kısa sürede hastanın dizini maksimum fonksiyona kavuşturarak, hastanın günlük hayata ve spora dönüşünü sağlamaktır. Rehabilitasyonun temel amaçları; ağrının azaltılması, eklem hareket açıklığının ve kas gücünün tam olarak sağlanması ve normal yürüyüş paterninin geri kazanılmasıdır. Rehabilitasyon protokollerinin en önemli bileşenleri; ağrı ve ödem kontrolü, eklem hareket açıklığı egzersizleri, kalça ve diz çevresi kaslarını içeren kuvvetlendirme egzersizleri ile denge ve propriosepsiyon çalışmalarıdır. Ameliyat edilen ekstremite üzerine ne zaman ve ne kadar yük verilebileceği ise ameliyat tekniğine, korreksiyon miktarına ve kullanılan implant türüne göre değişiklik göstermektedir. Diz çevresi osteotomileri sonrası oldukça yüksek oranda ameliyat öncesi seviyede ya da ameliyat öncesinden daha yüksek seviyede spora dönüş oranları bildirilmiştir. Ayrıca, spora dönüşte en önemli etkenlerden birinin hasta motivasyonu olduğu da ortaya konulmuştur. Sonuç olarak, doğru hasta seçimi ve doğru teknikle uygulanan diz çevresi osteotomileri sonrasında, uygulanacak doğru ve etkin bir rehabilitasyon programı ve yüksek hasta motivasyonu ile hastalar spor aktivitelerine ameliyat öncesi döneme göre aynı veya daha yüksek seviyede dönebilmekte, fonksiyonel kapasiteleri artmakta ve hayat kaliteleri yükselmektedir.
\end{abstract}

Anahtar sözcükler: diz; osteotomi; rehabilitasyon; spora dönüş
The purpose of rehabilitation after osteotomies around the knee joint is to enable the patient to return to daily life and sports activities, by providing maximum knee function as soon as possible, without damaging the osteotomy line and fixation. The main objectives of rehabilitation are; pain relief, full range of motion and muscle strength, and recovery of the normal gait pattern. The most important components of rehabilitation protocols are; pain and edema control, range of motion exercises, strengthening exercises involving hip and knee muscles, and balance and proprioception training. The decision about the timing and amount of weightbearing on the operated extremity varies according to the technique of surgery, the amount of correction and the type of implant used. High rates of return to same or higher levels of sports activities have been reported after osteotomies around the knee. It has also been shown that patient motivation is one of the most important factors in returning to sports. In conclusion; patients can return to sports activities at the same or a higher level compared to the preoperative period, and their functional capacity and quality of life are increased after osteotomies around knee performed with the right patient selection and the right technique, followed by an appropriate and effective rehabilitation program.

Key words: knee; osteotomy; rehabilitation; return to sports

\section{DIZ ÇEVRESI OSTEOTOMILERI SONRASI REHABILITASYON}

Diz çevresi osteotomileri sonrası rehabilitasyon programlarının amacı, osteotomi hattına ve fiksasyona zarar vermeden, hastanın dizini mümkün olan en kısa zamanda maksimum fonksiyona kavuşturmak, kişinin günlük hayata ve/veya spora dönüşünü hızlandırmaktır. Rehabilitasyon programlarının temel hedefleri; ağıı ve ödem kontrolü, diz eklem hareket açıklı̆ııın tam olarak sağlanması, alt ekstremite kas kuvvetinin ve normal yürüyüş paterninin kazandırılmasıdır. Propriyosepsiyon ve denge egzersizleri de fizik tedavi protokolünün önemli bileşenlerindendir. ${ }^{[1]}$

Ameliyat sonrası erken dönem ağrı ve ödem kontrolü, kuadriseps kas inhibisyonunu önlemesi açısından oldukça önemlidir. Soğuk uygulama ve elevasyon temel uygulamalardan ikisidir. Erken ameliyat sonrası dönemde ağrı ve ödemin derecesine göre sürekli soğuk

- Illetişim adresi: Prof. Dr. Tahsin Beyzadeoğlu, Bağdat Cad. No:333/8 Erenköy, 34738 İstanbul 
uygulamadan, günde 3-4 kez 10-20 dakika soğuk uygulamaya kadar değişen yöntemler mevcuttur. Ödem kontrolü için soğuk uygulama ve elevasyon gibi klasik yöntemlerin dışında interferansiyel akım ve aralıklı ultrason gibi elektroterapi cihazlarından da faydalanılabilir. ${ }^{[2,3]}$ Ağrı kontrolü de ameliyat sonrası rehabilitasyon programının etkili olması için oldukça önemlidir. Klasik analjezik ilaçlar, soğuk uygulama ve elevasyon gibi yöntemlerin yanı sıra ağrı kontrolü için transkutanöz elektrik stimülasyonu da (TENS) kullanılan etkili bir metottur. Manyetik alan tedavisi de analjezik etkinliği olan ve doku iyileşmesini arttıran bir diğer yöntemdir. ${ }^{[4,5]}$

Ameliyat sonrası yük verme derecesi osteotomi şekline ve kullanılan implanta göre değiş̧iklik gösterebilir. ${ }^{[6]}$ Noyes ve ark. açık kama yüksek tibial osteotomi ve Puddu plağı ile osteosentez sonrası hastaların 8. hafta sonunda tam yük verebileceklerini bildirmişlerdir. ${ }^{[7]}$ Aşık ve ark. ise Puddu plağı ve iliak greft ile birlikte allogreft kullandıkları açık kama yüksek tibial osteotomi ameliyatı yaptıkları hastalarında tam yüke 3 . ay sonunda geçmişlerdir. ${ }^{[8]}$ Lobenhoffer ve ark. ${ }^{[9]}$ ile Staubli ve ark. ${ }^{[10]}$ ise açık kama yüksek tibial osteotomi ve Tomofix plağı ile osteosentez sonrası tam yüke 8. ve 10. haftalarda geçtiklerini bildirmişlerdir. Taekuchi ve ark. ise Tomofix plağı ile osteosentez uyguladıkları açık kama osteotomilerde 2. haftanın sonunda hastalara tam yük verdirdiklerini bildirmişlerdir. ${ }^{[11]}$ Portner kapalı kama osteotomisi uyguladığı hastalara hemen, açık kama osteotomisi uyguladığı hastalara 4. hafta sonunda ve kombine osteotomi uyguladığı hastalara ise 8 . hafta sonunda tam yük verilebileceğini bildirmiştir. ${ }^{[12]} \mathrm{Biz}$, açık kama osteotomisi yaptığımız kendi olgularımızda, $10 \mathrm{~mm}$ 'den az düzeltme (korreksiyon) yapılmış ise 2-4. haftalarda; 10 mm'den fazla korreksiyon yapılmış ise 4-6. haftalarda tam yük verilmesine izin vermekteyiz.

Diz çevresi osteotomileri sonrası en önemli rehabilitasyon aşamalarından biri de eklem hareket açıklığı (EHA) egzersizleridir. Ameliyat sonrası 1. hafta içerinde başlanan EHA egzersizinde amaç 4. haftanın sonunda diz ekleminde tam harekete kavuşmaktır. ${ }^{[13]}$ Pasif EHA egzersizleri fizyoterapist eşliğinde yapılabileceği gibi sürekli pasif hareket (CPM - Continuous Passive Motion) cihazları da kullanılabilir. Aktif EHA egzersizleri hasta uyum gösterdiği sürece yapılabilir ve dizde $90^{\circ}$ 'lik fleksiyon derecesine ulaşılınca tam hareket açıklığını sağlamak için; sandalye yuvarlama, duvar kaymaları ve pasif kuadriseps gerdirme egzersizleri rehabilitasyon programına eklenebilir. ${ }^{[1]}$ EHA açısından en önemli noktalardan biri de hastanın ekstansiyon kısıtlılığının olmamasıdır. İkinci haftanın sonunda tam ekstansiyon kazanılmış olmalıdır. Eğer diz ekstansiyon kısıtlılığı mevcutsa diz üzerine 4-5 kilogram ağırlık konularak arka kapsülün gerilmesi ve dizin tam ekstansiyonunun kazanılması sağlanabilir. Ameliyat sonrası diz EHA'nın tam olarak sağlanabilmesinin kilit noktalarından biri de normal patellar hareketin geri kazanılmasıdır. ${ }^{[14]}$ Patellar hareket ameliyat sonrası ilk gün başlanabilir. Patellar mobilizasyon egzersizi dört düzlemde (süperior, inferior, medial, lateral) patella anatomisine ve fonksiyonuna uygun şekilde 10 saniye süreyle basınç uygulanarak yapılır. ${ }^{[1]}$ Ayrıca, aynı mobilizasyonu hastanın kendi başına da yapabilmesi için eğitim verilmelidir.

Güçlendirme egzersizleri diz çevresi osteotomileri sonrası rehabilitasyon protokolü aşamalarından biridir. ilk hafta izometrik olarak başlanan egzersiz programı ameliyat sonrası 7-8. haftalarda izotonik güçlendirme olarak devam eder. ${ }^{[13,15]}$ İzometrik egzersizlerini; kuadriseps egzersizleri, gluteal setting (gluteal kasların kasılıp bırakılması), düz bacak kaldırma ve aktif diz ekstansiyonu oluşturur. Bu egzersizlere ameliyat sonrası en erken 2. hafta, en geç 4-6. haftalarda olmak üzere kapalı kinetik zincir egzersizleri (parmak ucuna kalkma, mini-skuat (squat), leg-press vb.) eklenir ve üç ay boyunca devam edilir. ${ }^{[1,16]}$ Ameliyat sonrası 6-8. haftalarda başlanacak olan izotonik hamstring ve kuadriseps güçlendirme egzersizleri, düz bacak kaldırma plus egzersizi ve kalça abdüktör-addüktör kaslarını güçlendirme egzersizleri, diz çevresi ostetomisi sonrası rehabilitasyon protokolünde önemli bir yer tutmaktadır.

Ameliyat sonrası 8-10. haftalarda denge ve propriyosepsiyon eğitimi ve egzersizlerine başlanır; 6 . aya kadar devam edilebilir. Engelden atlama yürüyüşü, çift bacak ve tek bacak denge egzersizi, pertürbasyon yöntemi denge ve propriyosepsiyon egzersizleri için başlıca kullanılan yöntemlerdir. ${ }^{[17]}$ Engelden atlama yürüyüşü ekstremiteler arasındaki asimetriyi azaltmaktadır. Çift bacak ve tek bacak denge egzersizleri de bacağın yük taşıma güvenini arttırırken, diz eklemi pozisyon duyusunun gelişmesine de yardımcı olur. ${ }^{[1]}$ Bu egzersizi daha da zorlaştırmak için mini trambolin ve dengesiz platform kullanılabileceği gibi pertürbasyon tekniği de kullanılabilir. ${ }^{[17]}$ Diz çevresi osteotomileri sonrasında kendi hastalarımıza uyguladığımız ameliyat sonrası rehabilitasyon protokolü Tablo 1'de özetlenmiştir.

\section{DIZ ÇEVRESI OSTEOTOMILERI SONRASI SPORA DÖNÜŞ}

Osteotomi sonrası takip süresinin, planlanan ekstremite dizilimine ulaşımasının, hastanın genel durumunun ve cerrahi prosedürün sonuçlar üzerinde etkisi olduğu kadar yaş ve ameliyat öncesi fiziksel 
Tablo 1. Diz çevresi osteotomileri sonrasında kendi hastalarımıza uyguladığımız ameliyat sonrası rehabilitasyon protokolü

\begin{tabular}{lll}
\hline 0-4 Hafta & 4-6 Hafta & 6-12 Hafta \\
\hline Anti ödem tedavi & İzotonik egzersizler & İzotonik egzersizler \\
Pasif EHA egzersizleri & İzokinetik egzersizler & İzokinetik egzersizler \\
İzometrik kuadriseps egzersizleri & Ayakta ağırlık aktarma ve denge & $\begin{array}{l}\text { Denge, propriosepsiyon ve yürüme } \\
\text { egzersizleri }\end{array}$ \\
Aktif yardımlı (asistif) EHA egzersizleri & egzersizleri & Desteksiz tam yük vererek yürüme \\
Patella ve diz eklemi mobilizasyonları & Destekli dirençli egzersizler & \\
Ameliyat sonrası 2. haftada çift kanadyen ile vücut & Tek kanadyen ile vücut ağırlığının & \\
ağılığının tolere edilebilir kadarını vererek diz tam & tamamına yakınını vererek normal & \\
ekstansiyonda yürüme & paternde yürüme & \\
Ameliyat sonrası 4. haftada tam yük vererek yürüme & & \\
\hline EHA, eklem hareket açıklı̆ı̆. & &
\end{tabular}

Tablo 2. Ekhtiari ve ark.'ın sistemik tarama çalışması [22]

\begin{tabular}{|c|c|c|c|c|}
\hline & Çalışma sayısı & Hasta sayısı & Ameliyat öncesi & Ameliyat sonrası \\
\hline \multicolumn{5}{|l|}{ Spora dönüş oranı } \\
\hline Total & 11 & 250 & 250 & $218(\% 87,2)$ \\
\hline Açık kama & 9 & 173 & 173 & $157(\% 90,8)$ \\
\hline Kapalı kama & 1 & 23 & 23 & $23(\% 100)$ \\
\hline \multicolumn{5}{|c|}{ Aynı veya daha yüksek aktiviteli spora dönüş } \\
\hline Total & 13 & 378 & 378 & $297(\% 78,6)$ \\
\hline Açık kama & 10 & 216 & 216 & $184(\% 85,2)$ \\
\hline Kapalı kama & 1 & 23 & 23 & $22(\% 95,7)$ \\
\hline Temel aktivite düzeyi & 6 & 28 & 28 & $28(\% 100)$ \\
\hline
\end{tabular}

aktivite düzeyi de sonuçlar üzerinde oldukça önemli etkiye sahiptir. ${ }^{[18-20]}$ Literatürde diz çevresi osteotomileri sonrası spora dönüş ile ilgili yayınlar bulunmaktadır. ${ }^{[21-24]}$ Bonnin ve ark. yayımladıkları çalışmalarında yüksek tibial osteotomi yapılan 139 hastanın sonuçlarını bildirmişlerdir. Bu çalışmaya göre hastaların \%20 ,8'inin ameliyat öncesine göre daha yüksek seviyede, $\% 44,6$ 'sının ise aynı seviyede spora döndügüü belirtilmiştir. Hastaların \%63'ü yüksek tibial osteotomi sonrası dizini normal hissettiğini belirtmiştir. ${ }^{[21]}$ Ekhtiari ve ark. yaptıkları sistemik tarama çalışmalarında yüksek tibial osteotomi ameliyatı sonrası hastaların \%87,2'sinin spora döndüğünü ve bu hastaların $\% 78,6$ 'sının ise aynı seviyede ve daha yüksek seviyede sportif aktivitede bulunabildiğini belirtmişlerdir (Tablo 2). [ ${ }^{[2]}$

Salzmann ve ark. yüksek tibial osteotomi ameliyatı geçiren 65 hasta üzerinde yaptıkları çalışmada ise hastaların \%87,9'unun ameliyat öncesi spor aktivitesinde bulunabildiğini, bu oranın ameliyat sonrası \%90,9'a yükseldiğini bildirmişlerdir. ${ }^{[23]}$ Saragaglia ve ark. diz valgus osteotomisi yapılan 83 hastanın 71'inin (\%83) spor aktivitesine geri döndüğü $66^{\prime} \operatorname{sının~}(\% 79,5)$ ise ameliyat öncesine göre aynı veya daha yüksek seviyede spor aktivitesinde bulunabildiğini belirtmişlerdir. ${ }^{[25]}$ Bastard ve ark. ise 60 yaşından küçük yüksek tibial osteotomi ameliyatı olan 30 hastanın ameliyat sonrası 1. yılda, hepsinin spor aktivitesine geri döndüğünü, \%73,3'ünün ameliyat öncesi ile aynı seviyede, $\% 23,3$ 'ünün ise daha yüksek seviyede spor yapabildiğini bildirmişlerdir. ${ }^{[26]}$

Voleti ve ark.'nın distal femoral osteotomi ameliyatı geçiren 13 atlet hastada yaptıkları çalışmada, sporcuların ameliyat sonrası ortalama 11. ayda yaptıkları spora sorunsuz şekilde döndükleri bildirilmiştir. ${ }^{[27]}$ Başka bir çalışmada ise Beyzadeoğlu ve ark., 21 hastanın 24 dizine yaptıkları osteotomi ile kombine yaptıkları yüzey kaplama artroplastisi ameliyatları sonrası, tüm hastalarında aynı düzeyde spora dönüş bildirmişlerdir. ${ }^{[28]}$

Spora dönüşe katkıda bulunan en önemli faktörlerden biri de hasta motivasyonudur. ${ }^{[25]}$ Saragaglia ve ark.'nın yaptığı çalışmada diz valgus osteotomisi yapılan hastalarda motivasyonu yüksek olanların ameliyat sonrası Tegner skorlarının, motivasyonu düşük olanlara göre anlamlı oranda yüksek olduğu 
belirtilmiştir. ${ }^{[25]}$ Bonnin ve ark.'nın yaptığı çalışma da benzer sonuçları ortaya koymuştur. Yüksek tibial osteotomi yapılan ve motivasyonu yüksek olan hastaların \%66'sı yüksek seviyeli spor aktivitesinde bulunabiliyorken bu oran motivasyonu düşük hastalarda \%28 olarak belirtilmiştir. ${ }^{[21]}$

Sonuç olarak, diz çevresi osteotomilerinde ameliyat sonrası uygulanan doğru ve etkili rehabilitasyon programı ve yüksek hasta motivasyonu sonuçlar üzerinde en az doğru endikasyon ve teknik kadar önemli yer tutmaktadır. Etkili bir rehabilitasyon programı uygulanan ve yüksek motivasyona sahip olan hastalar spor aktivitelerine ameliyat öncesi döneme göre daha yüksek seviyede dönebilmekte, fonksiyonel kapasiteleri artmakta ve hayat kaliteleri yükselmektedir.

\section{KAYNAKLAR}

1. Külcü DG, Bombacı H. Yüksek Tibial Osteotomi ve Distal Femoral Osteotomi Sonrası Rehabilitasyon. İçinde: Esenkaya i, Özenci M, Kocabey Y, Bombacı H, Köse Ö. Diz Çevresi Osteotomileri, Bölüm 25. İstanbul: İstanbul Tıp Kitabevi; 2018. ss.197-202.

2. Koyuncu H, Karacan I. Fiziksel Tip ve Rehabilitasyonda Elektroterapi. Özel Akım Türleri ve Uygulamaları. Ankara: Güneş Tıp Kitabevi; ss.113-5.

3. Öztürk C, Aşit R. Tedavide Sıcak ve Soğuk. İçinde: Oğuz H, Dursun E, Dursun N, editörler. Tıbbi Rehabilitasyon. İstanbul: Nobel; 2004. ss.333-53.

4. Gökşen N, Çaliş $M$, Doğan S, Çaliş HT, Özgöçmen S. Magnetic resonance therapy for knee osteoarthritis: a randomized, double blind placebo controlled trial. Eur J Phys Rehabil Med 2016;52(4):431-9. https://www. minervamedica.it/en/journals/europa-medicophysica/ article.php?cod=R33Y2016N04A0431

5. Tekeoğlu I. Rehabilitasyonda Alternatif Yöntemler. İçinde: Oğuz H, Dursun E, Dursun N, editörler. Tıbbi Rehabilitasyon. İstanbul: Nobel; 2004. ss.459-75.

6. Brinkman JM, Luites JWH, Wymenga $A B$, van Heerwaarden RJ. Early full weight bearing is safe in open-wedge high tibial osteotomy. Acta Orthopaedica 2010;81(2):193-8. Crossref

7. Noyes FR, Mayfield W, Barber-Westin SD, Albright JC, Heckmann TP. Opening wedge high tibial osteotomy: an operative technique and rehabilitation program to decrease complications and promote early union and function. Am J Sports Med 2006;34(8):1262-73. Crossref

8. Aşık M, Şen C, Kılıç B, Göksan S B, Çiftçi F, Taşer ÖF. High tibial osteotomy with Puddu plate for the treatment of varus gonarthrosis. Knee Surg Sports Traumatol Arthrosc 2006;14:948-54. Crossref

9. Lobenhoffer P, Agneskirchner J, Zoch W. Open valgus alignment osteotomy of the proximal tibia with fixation by medial plate fixator. [Die offnende valgisierende Osteotomie der proximalen Tibia mit Fixation durch einen medialen Plattenfixateur.] Orthopade 2004;33(2):153-60. Crossref

10. Staubli AE, De Simoni C, Babst R, Lobenhoffer P. TomoFix: a new LCP-concept for open wedge osteotomy of the medial proximal tibia--early results in 92 cases. Injury 2003;34(Suppl 2):55-62. Crossref

11. Takeuchi $R$, Ishikawa $H$, Aratake M, Bito $H$, Saito I, Kumagai K, Akamatsu Y, Saito T. Medial opening wedge high tibial osteotomy with early full weight bearing. Arthroscopy 2009;25(1):46-53. Crossref
12. Portner O. High Tibial Valgus Osteotomy: Closing, Opening and Combined? Patellar Height as a Determining Factor. Clin Orthop Relat Res 2014;472(11):3432-40. Crossref

13. Aalderink KJ, Shaffer M, Amendola A. Rehabilitation Following High Tibial Osteotomy. Clin Sports Med 2010;29(2):291301. Crossref

14. Boling MC, Beutler A, Patellafemoral Injuries. In: Starkey C, editor. Athletic Training Sports Medicine, 5th ed. Burlinton: World Health-quarters; 2013. pp.189-217.

15. Anbari A. Proximal Tibial and Distal Femoral Osteotomy. In: Cole BJ, Gmoll AH, editors. Biologic Joint Reconstruction Alternatives to Arthroplasty. Thorofare: SLACK; 2009. pp.205-12.

16. Noyes FR, Heckmann TP, Barber-Westin SD. Rehabilitation after tibial and femoral osteotomy. In: Noyes FR, BarberWestin SD, editors. Noyes' Knee Disorders: Surgery, Rehabilitation, Clinical Outcomes, 2nd ed. Philadelphia: Elsevier; 2017. p.858-67.

17. Power B, Rivard J, Hayner B, Grimsby O. Exercise Rehabilitation of the Knee. In: Grimsby O, Rivard J, editors. Science, Theory and Clinical Application in Orthopaedic Manuel Physical Therapy. USA. Taylorsville; 2009. pp.71-160.

18. AgneskirchnerJD, Hurschler C, Wrann CD, Lobenhoffer P. The effects of valgus medial opening wedge high tibial osteotomy on articular cartilage pressure of the knee: a biomechanical study. Arthroscopy 2007;23(8):852-61. Crossref

19. Hernigou P, Medevielle D, Debeyre J, Goutallier D. Proximal tibial osteotomy for osteoarthritis with varus deformity. A ten to thirteen-year follow-up study. J Bone Joint Surg Am 1987;69(3):332-54. Crossref

20. Hunter DJ, Sharma L, Skaife T. Alignment and osteoarthritis of the knee. J Bone Joint Surg Am 2009;91(Suppl 1):85-9. Crossref

21. Bonnin MP, Laurent JR, Zadegan F, Badet R, Pooler Archbold $\mathrm{HA}$, Servien E. Can patients really participate in sport after high tibial osteotomy? Knee Surg Sports Traumatol Arthrosc 2013;21(1):64-73. Crossref

22. Ekhtiari S, Haldane CE, de Sa D, Simunovic N, Musahl V, Ayeni OR. Return towork and sport following high tibial osteotomy: a systematic review. J Bone Joint Surg Am 2016;98(18):1568-77. Crossref

23. Salzmann GM, Ahrens P, Naal FD, El-Azab H, Spang JT, Imhoff $A B$, Lorenz S. Sporting activity after high tibial osteotomy for the treatment of medial compartment knee osteoarthritis. Am J Sports Med 2009;37(2):312-8. Crossref

24. Odenbring S, Tjornstrand B, Egund N, Hagstedt B, Hovelius $L$, Lindstrand $A$, Luxhöj T, Svanström A. Function after tibial osteotomy for medial gonarthrosis below age 50 years. Acta Orthop Scand 1989;60(5):527-31. Crossref

25. Saragaglia D, Rouchy RC, Krayan A, Refaie R. Return to sports after valgus osteotomy of the knee joint in patients with medial unicompartmental osteoarthritis. Int Orthop 2014;38(10):2109-14. Crossref

26. Bastard C, Mirouse G, Potage D, Silbert H, Roubineau F, Hernigou P, CH Flouzat-Lachaniette. Return to sports and quality of life after high tibial osteotomy in patients under 60 years old. Orthop Traumatol Surg Res 2017;103(8):118991. Crossref

27. Voleti PB, Wu IT, Degen RM, Tetreault DM, Krych AJ, Williams RJ. Successful Return to Sport Following Distal Femoral Varus Osteotomy. Cartilage 2019;10(1):19-25 Crossref

28. Beyzadeoglu T, Onal A, Caglar MM. Inlay Joint Resurfacing and High Tibial Osteotomy (HTO) in Middle-Aged Athletes. In: Doral MN, Tandogan RN, Mann G, Verdonk R, editors. Sports Injuries: Prevention, Diagnosis, Treatment and Rehabilitation. Springer-Verlag; 2014. pp.1-10. Crossref 